\title{
Preferential Admission Policies for Ethnic Minority Students in Yunnan: Help or Hindrance
}

\author{
Dongyuan Deng \\ Suranaree University of Technology, Thailand \\ https://orcid.org/0000-0002-7003-8157 \\ Sirinthorn Seepho \\ Suranaree University of Technology, Thailand \\ https://orcid.org/0000-0002-5048-5435 \\ Andrew Lian \\ Suranaree University of Technology, Thailand \\ https://orcid.org/0000-0002-5812-3017
}

\begin{abstract}
This research project took Yunnan (YN), the most southwestern province of China and a frontier province with the largest number of ethnic minorities along with multi-ethnic languages and abundant ethnic cultures, as a specific case. It studied both the current situation of minority education and the necessity for Preferential Admission Policies (PAPs) in the particular stage of the national college entrance examination (NCEE) from a social perspective. Quantitative statistics was used to analyze data from the different education levels of the minority groups. Document analysis and in-depth interviews with four groups of participants (exclusive ethnic minority university students (EEMs), university teachers, administrators and provincial officials of Yunnan Province) were conducted to explore the rationality and feasibility of PAPs. The findings reveal that PAPs are indeed justified in Yunnan's multi-ethnic social context, at the same time, geographical remoteness and regional gaps, socioeconomic determinants, and linguistic barriers contributed to the need for PAPs at present under the average level of minority education in Yunnan.
\end{abstract}

Keywords: Yunnan; ethnic minority education; Preferential Admission Policies; entrance examination; social context

\section{Introduction}

\subsection{Overview of Ethnic Minorities in China and Yunnan}

The People's Republic of China (PRC) is a multicultural, multi-ethnic, and unified country with a written history of more than 4,000 years, and it is home to 
56 ethnicities. The Han majority makes up about $91.51 \%$ of the total population in the mainland, whereas other ethnic groups constitute $8.49 \%$. The term "ethnic minority" refers to the 55 non-Han China's officially recognized ethnic groups in the PRC. They are defined as "historically constituted, stable community of people, formed based on a common language, territory, economic life, and psychological make-up manifested in a common culture" (Mackerras, 2003, p.2). They share "a language, an area, an economic life, a culture" (Gladney, 1994, p.98) and "an awareness of belonging to the same group" (Campos, Ren \& Petrick, 2016, p.258). The total population of the minority groups has increased to over 113.79 million, and most of these ethnic groups inhabit in frontier and rural areas with their own distinctive cultures and customs (Guo, et al., 2019).

Yunnan was reported by the government authorities of the 6th National Population Census of China ${ }^{1}$ that currently the total population of Yunnan province is 45.966 million. 30.629 million are Han, which comprise $66.63 \%$ of the Yunnan's population. Yunnan contains 52 out of the 55 ethnic minorities in China, among whom 25 minority populations exceed 5,000 people and 15.337 million in total, and they composes of $33.37 \%$ of the whole population of Yunnan (Cai, 2014). Meanwhile, statistics shows that nearly one-third of the povertystricken counties $^{2}$ in Yunnan and some other western parts of China are primarily inhabited by ethnic minority people (Yang, 2005; Adamson \& Xia, 2011). These regions are considered as less developed and "the most economically deprived regions in China" (Feng \& Cheung, 2010, p.258). In practice, ethnic minority education is of great significance for Yunnan's socioeconomic development.

\subsection{PAPs for Ethnic Minorities in the NCEE}

\section{Key Regulations of PAPs}

Despite the rapid economic development of China, it is evident that there is unequal access to good quality education for people. The vast differences between China's prosperous eastern coastal provinces and the poor western inland provinces have widened the gap. The differences between urban and rural areas are in the same situations (Adamson \& Feng, 2009; Sunodula \& Feng, 2011). In minority education, PAPs are designed to recruit minority students by lowering the required scores for the NCEE according to the level of economic development of some particular concentrated areas of ethnic minorities ${ }^{3}$, and then by giving those ethnic minority students priority in admission to higher education over the Han majority. The most recent PAPs have been implemented since 2000 by taking both ethnicity and level of socioeconomic development as

\footnotetext{
${ }^{1}$ The National Population Census of China started in 1953. It was usually held once every ten years ever since 1980. The $6^{\text {th }}$ National Population Census of China was conducted in November 2010 and released in 2011, and so far, the data are the latest.

${ }^{2}$ There are five levels of primary administrative divisions in China: provincial level (1st), prefectural level (2nd), county-level (3rd), township level (4th), and village level (5th).

${ }^{3}$ Concentrated areas of ethnic minorities: those ethnic community areas with people mostly from the same dominant ethnic minority group.
} 
criteria. Some critical regulations on bonus points are illustrated as follows (Bao \& Liu, 2015; Hu \& Ga, 2016; Guan, 2019).

First, minority college applicants from border counties receive 30 bonus points in the NCEE. Han applicants who were born in the concentrated areas of ethnic minorities or the families have lived there for ten or more years earn 20 bonus points. This item gives ethnic minorities a slight edge over Han students from the same place. Second, the PAPs of Yunnan regulate that university applicants from China's interior regions can obtain ten bonus points on their NCEE. 19 ethnicities in buffer and inland zones (including the Hani, Dai, Miao, Lisu, La, Wa, Jingpo, Yao, Bulang, Nu, Achang, Pumi, Deang, Dulong, Zang, Mongol, Jinuo, Shui, and Buyi) may receive ten bonus points. However, Hui, Bai, urban Zhuang, urban Yi, and Manchu applicants do not accept any bonus points. Third, for underdeveloped counties from the concentrated areas of ethnic minorities in nomadic pastoral areas and mountainous highlands, ethnic candidates may apply for 20 bonus points in the NCEE. Fourth, ethnic minority applicants are frequently given priority over Han applicants in college admission when they have the same college admission scores if they are from the Hui, Naxi, Bai, Manchu, urban Yi, and civic Zhuang ethnic groups. Meanwhile, the methods or assessment for students' enrollment in vocational schools, adult education, and technical secondary schools are similar to the regulations previously mentioned.

\section{PAPs for Ethnic Minorities in the NCEE}

The Ministry of Education (MOE) in China has adopted PAPs to lower admission scores for ethnic minority students in the NCEE. To know the background of Yunnan's PAPs for minority college applicants, it is necessary to have a comprehensive understanding of the history and social functions of China's NCEE. The NCEE began in 1952 and has been considered by the public as the academic criteria for college entrance throughout China ever since then. The NCEE constantly plays a critical role in Chin's education only with the interruption of the ten-year Cultural Revolution (1966-1976) (Gorter \& Durk, 2015). In China, the purpose of the NCEE is to select the top students who are usually those with higher examination scores to gain access to university, and to allocate limited high-quality educational resources based on students' academic performance rather than social status or their family conditions. China has set PAPs to redress the inequality in college enrollment while maintaining the practical implementation of unified NCEE scores because minority groups are often disadvantaged due to certain "historical factors as well as geographic remoteness" (Wan \& Jun, 2008, p.140). If only one cutoff score is adopted nationally, applicants from some concentrated ethnic minority communities and remote regions will lose their opportunities to receive higher education, which will absolutely result in disparity in education. Therefore, for decades some ethnic minority students have had to resort to PAPs, which lowers the "entrance threshold" (Verhoeven \& Zhang, 2016). As a result, a wide range of the minority population (which amounts to one-fourth of the total minority population) that lives in the concentrated ethnic areas, are mostly integrated with the Han and thus have become beneficiaries of PAPs (Sautman, 2010). 


\subsection{Novelty of This Study}

Although there have been some previous research programs concerning ethnic minority education in China, most of them focused on bilingual or multilingual education problems (Yang, 2005; Sunuodula \& Feng, 2011; Adamson \& Feng, 2014; Wang, 2015). Some emphasized on minority education situations in specific ethnic autonomous regions or provinces such as Tibet, Mongolia, Xinjiang, Guizhou etc. (Sunuodula \& Cao, 2015; Postiglione, Jiao \& Tsering, 2009; Dong, Gou, Wang \& Qiu, 2015; Ba, 2009; Finifrock \& Schilken, 2015). So far, only a few research programs have considered preferential policies (Wang, 2009; Teng \& Ma, 2009; Zhou, 2009). But most of these studies were carried out in a macroscopic perspective, in which a general situation of ethnic minorities in China was analyzed. In 2015, Professor Yuan and his colleagues surveyed on trilingual education in Yunnan (Yuan et al., 2015). That is one of the minimal indigenous research involved Yunnan minority education, where, as mentioned above, is a province with the most diverse ethnic cultures and ethnic languages in China. Above all, studies on PAPs for ethnic minority students at the critical moment of the NCEE in the context of Yunnan are still rare. This study hopes to fill these gaps in the perspective of PAPs for ethnic minority students in Yunnan.

\section{Research Purposes and Questions}

\subsection{Purposes s of the Study}

The purposes of this study were to obtain a picture of the minority education situation of Yunnan, China, as this province is uniquely characterized by multiethnic cultures and includes various and diverse ethnicities. Also, it aimed to explore the factors which possibly determine the necessity of PAPs in the NCEE from a social perspective, uniquely combining the local ethnic education condition with PAPs situation together.

\subsection{Questions of the Study}

To achieve the objectives, the study attempted to answer the following two questions:

(1) What is the current situation of ethnic minority education in Yunnan?

(2) What are the factors that determine the necessity of PAPs' implementation for ethnic minorities in Yunnan in the NCEE?

\subsection{Limitations of the Study}

The results of this study cannot be generalized to all minority students because the sample chosen in this study does not include all the minorities in Yunnan, China. Moreover, the data elicited from the 6th National Population Census can only work as a reference because this is the latest information available. This study was conducted in Yunnan, China, from 2017 to 2019. 


\section{Methodology}

The study adopted a mixed-methods approach with the qualitative method being dominant. To understand the general situation of the ethnic minority education level of Yunnan, the descriptive statistics was used to illustrate the status of minority education in Yunnan. Concerning the qualitative approach, based on the education level of the ethnic minority samples, a semi-structured interview was conducted to elicit data from different ethnic participants, whom will be explained in the following part, to comprehend the rationality and feasibility of PAPs implementation in Yunnan context. By using these two methods, it enabled the researcher to confirm findings from various data sources and develop an understanding of the overall situation. Besides, the researcher used a longitudinal approach, starting from primary education to higher education. Simultaneously, horizontal multiple comparisons and analysis of different ethnicities, including the Han, were carried out to obtain an objective and comprehensive view of the research.

\subsection{Research Participants}

\section{Samples for the Quantitative Approach}

Although Yunnan is a province with a large number of ethnicities, there are only 15 exclusive ethnic minorities (EEMs) including Hani, Bai, Wa, Naxi, Jingpo, Bulang, Pumi, Dai, Lisu, Lahu, Jinuo, Achang, Nu, Deang, and Dulong. EEMs mean those ethnic minorities who only live in Yunnan province. As these 15 EEMs are mostly representatives of the local ethnic minorities of Yunnan (Sun, et al., 2013), therefore, the study mainly chose the 15 EEMs as samples to analyze the minority education situation in Yunnan province. The data were obtained from the 6th National Population Census, China.

\section{Samples for the Qualitative Approach}

The samples for interviewing consisted of four groups of people, i,e. EEMs, university teachers and administrators, and officials in Yunnan. About four representative interviewees for each 15 EEM groups of subjects (60 students) participated in both the individual and focus group interviews. They were randomly recommended by their teachers and voluntarily joined. Also, five Han students were included for some specific comparison. Besides, four university teachers with various work experiences on minority education programs were selected purposefully from four government-funded universities which are wellknown for the enrollment of local ethnic minority college applicants from Yunnan, i.e., Yunnan Minzu University (YMU), Dali University (DU), ChuXiong Normal University (CNU), and Kunming University of Science and Technology (KUST). Also, three administrators were respectively from YMU, DU, and CNU, and another two officials were from Yunnan Provincial Department of Education (YPDE) and Kunming Education Bureau (KEB). Altogether, 74 participants were investigated as a mixture of different ethnicities, from different areas of study and with a longer or shorter term of learning and work experience by using both random and purposive sampling methods. The use of multiple resources embedded EEM groups and four university sites enabled data triangulation and provided reliability in the findings. 
Table 1. Basic information on the participants

\begin{tabular}{|c|c|c|c|}
\hline Participants & Number & Method of selection & Notes of sampling \\
\hline EEMs \& Han & 65 & random sampling & $\begin{array}{l}4 \text { for each of the } 15 \text { EEMs, } \\
\text { plus } 5 \text { Han students }\end{array}$ \\
\hline University teachers & 4 & purposive sampling & YMU, DU, CNU, KUST \\
\hline Administrators & 3 & purposive sampling & YMU, DU, CNU \\
\hline Officials & 2 & purposive sampling & YPDE and KEB \\
\hline
\end{tabular}

Table 2. Demographic information on the EEMs and Han participants

\begin{tabular}{|c|c|c|c|c|}
\hline Universities & YMU & KUST & DU & $\mathrm{CNU}$ \\
\hline Individual interview (No) & 20 & 16 & 12 & 12 \\
\hline $\begin{array}{l}\text { Focus group interview } \\
\text { (Ethnicity-No) }\end{array}$ & Naxi-5 & Han-5 & Bai-5 & Deang-5 \\
\hline Level of education & BA \& MA & BA \& MA & BA & BA \\
\hline Location (City) & Kunming & Kunming & Chuxiong & Dali \\
\hline
\end{tabular}

Table 3. Demographic information on teacher participants

\begin{tabular}{lllll}
\hline Samples & Teacher1 & Teacher2 & Teacher3 & Teacher4 \\
\hline University & YMU & KUST & CNU & DU \\
Professional Title & EFL lecturer & EFL Asso.Prof. & EFL lecturer & EFL Prof. \\
Pseudonym & Ms Du & Mrs Gao & Mr Li & Mrs Mei \\
Ethnicity & Zhuang & Han & Miao & Bai \\
Years of Teaching & 6 & 20 & 8 & 25 \\
\hline
\end{tabular}

Table 4. Demographic information on administrative and official participants

\begin{tabular}{llllll}
\hline Samples & Adm-1 & Adm-2 & Adm-3 & Official-1 & Official-2 \\
\hline Work unit & YMU & DU & CNU & YPDE & KEB \\
Pseudonym & Mrs Haiye & Dr Yangzi & Mr Lin & Mr He Zhi & Mr Dong Ying \\
Ethnicity & Zhuang & Bai & Han & Naxi & Han \\
Years of working & 16 & 12 & 21 & 22 & 18 \\
\hline
\end{tabular}

\subsection{Data Collection}

\section{Quantitative Data for Research Question 1}

All data on the 15 EEMs and the Han of Yunnan were collected through the official website of the 6th National Population Census of China. The percentage of the index for describing the situation of minority education in Yunnan were measured (see Table 5, 6).

\section{Qualitative Data for Research Question 2}

As "the interview is the most widely used method of generating data in qualitative social research" (Nunkoosing, 2005, p.698), a semi-structured interview was utilized to explore EEMs' growing up experiences and their opinions of PAPs. The meetings were organized at both the interviewer's and interviewees' convenience and were open-ended to allow for complementarity and expansion of related questions. Each in-depth individual interview lasted approximately 20 minutes, and the time for the focus group interview was from half an hour to one hour. Most of the interviews took place on the campus of the 
4 sample universities, in classrooms, office, or on outdoor benches. Chinese was the primary language used for the interviews. The English language was also employed when it became necessary. Above all, confidentiality was the central policy. Based on the four different groups of participants, opinions obtained from the EEMs described their educational experiences and perceptions of PAPs. Besides, the data of the teachers concerned the consequences and influence of PAPs towards ethnic minorities. Moreover, the statements made by the administrators and officials explained the contents of PAPs and their original purposes. Also, a review of all the related policy documents was conducted, and the materials were obtained from the Yunnan provincial library.

\subsection{Data Analysis}

Research Question 1: All data elicited from the 6th National Population Census of China were fed into the SPSS 2.0 data analysis program for the statistical frequency to measure the percentage of the index for describing and generalizing the situation of minority education level in Yunnan.

Research Question 2: A content and thematic analysis were carefully conducted with the interview data and policy document analysis. In the process of analyzing the data, three necessary steps, i.e., domains, core ideas, and a crossanalysis were used to construct common themes across the participants (Hill, et al., 2005). In order to establish the reliability of the data, intra-coding was employed, and afterwards, the data were developed into categories and themes through refinement, comparison, and analysis. Complicated interactions among these categories and themes were also examined. After a cross-analysis and a member-checking on the data, the essential extracts of the interview transcripts were elicited, and later translated into English from Chinese.

\section{Results and Discussion}

Historically speaking, PAPs for minorities have figured most prominently in Yunnan's implementation of central laws and policies. In Yunnan, the concentrated areas of ethnic minorities have traditionally suffered from the low level of economic and educational development. These areas are also confronted with a shortage of human resources. The government has implemented a series of particular preferential policies to promote the local population increase, develop education, offer human resources training programs, and encourage the regional economic development to alleviate poverty. PAPs are one method to increase the proportion of minority students who can access higher education.

\subsection{Current Situation of Minority Education in Yunnan}

To understand the new situation of the minority education in Yunnan, the study took the 15 EEM groups as well as the Han of Yunnan as samples. Relevant data of population were collected from the 6th National Population Census of China, and the researcher measured the percentage of the index for describing and summarizing the situation of minority education in Yunnan by using SPSS 2.0 for frequency analysis of the statistical data. 
Table 5. Education Situation of the 15 EEMs in Yunnan, China

\begin{tabular}{lccccc}
\hline $\begin{array}{c}\text { Population of } \\
\text { Education }\end{array}$ & Uneducated & $\begin{array}{c}\text { Primary } \\
\text { School }\end{array}$ & $\begin{array}{c}\text { Junior High } \\
\text { School }\end{array}$ & $\begin{array}{c}\text { Senior High } \\
\text { School }\end{array}$ & $\begin{array}{c}\text { Higher } \\
\text { Education }\end{array}$ \\
\hline YN (N=million) & 3.393 & 20.043 & 12.591 & 38.131 & 26.361 \\
Percentage (\%) & 7.99 & 47.19 & 29.64 & 8.98 & 6.21 \\
\hline Han (N=million) & 1.954 & 12.653 & 9.028 & 28.593 & 20.095 \\
Percentage (\%) & 6.86 & 44.39 & 31.67 & 10.03 & 7.05 \\
\hline EEMs & 7.322 & 31.149 & 1.568 & 4.227 & 2.840 \\
(N=million) & 11.96 & 50.88 & 25.61 & 6.91 & 4.64 \\
Percentage (\%) & & & & \\
\hline
\end{tabular}

(Source of the population: https://www.yearbookchina.com/)

Note: The data for the educated population here only included students above six years old, which meant the data of children under six years old (school age) were excluded. For the population, three decimal places were used, while for the percentage, only two decimal places were adopted. Higher education here covered college, university, and postgraduate levels of education.

Based on the data, Yunnan education was mostly focused on the stage of primary education. Its education level fell behind many other provinces in the eastern part of China. Furthermore, almost half of the EEMs finished their primary school (50.88\%), a quarter of them could continue with junior high school $(25.61 \%)$. A small number of them were able to further rise to senior high school $(6.91 \%)$, and only a few of them finally reached higher education $(4.64 \%)$.

What's more, the data also revealed that the average years of Yunnan students' schooling was 7.57 years. For the Han, it was 7.85 years, while for the EEMs, it was 6.93 years. Among the different minorities, Naxi (8.53 years), Bai (8.12 years), and Jinuo (7.65 years) showed a higher than average level of education in Yunnan, while the other 12 ethnic minority groups were lower. Compared with the Han proportion $(7.05 \%)$ at a higher education level, the EEMs percentage was $4.64 \%, 2.41 \%$ lower than that of the Han.

Why is a higher education of such great significance in minority education development? Chen's finding showed that the status quo in the minority education of Yunnan is still far from satisfactory (Chen, 2019). In China's context, for ethnic minorities, higher education functions not only to cultivate the high-quality talents of minorities to serve the government's unity and stability, but also to accelerate the socioeconomic development of these minority regions (Feng \& Cheung, 2010).

Article 8 of the Higher Education Law of the PRC stipulates that:

In light of the characteristics and needs of ethnic minority groups, the PRC assists and supports the development of higher education in regions inhabited by ethnic peoples to cultivate ethnic talent and train senior specialists among them (National People's Congress, 2018, p. 3). 
In reality, concentrated areas of ethnic minorities in Yunnan are significantly in need of a strengthening of their development through the talent available from higher education. Based on statistics of the 15 EEMs, the researcher statistically calculated the numbers of illiterate/ semi-illiterate and those in higher education, as shown below (Table 6).

Table 6. The proportion of illiterate/ semi-illiterate and higher education of the 15 EEMs in Yunnan (\%)

\begin{tabular}{lccccccccc}
\hline Ethnicity & YN & Han & EEMs & Hani & Bai & Dai & Lisu & Lahu & Wa \\
\hline $\begin{array}{l}\text { Illiteracy/ } \\
\text { Semi-illiteracy }\end{array}$ & 7.99 & 6.86 & 11.96 & 14.70 & 5.74 & 11.52 & 18.80 & 15.91 & 14.22 \\
\hline $\begin{array}{l}\text { Higher } \\
\text { education }\end{array}$ & 6.21 & 7.05 & 4.64 & 2.93 & 7.63 & 3.91 & 2.60 & 2.67 & 2.44 \\
\hline Ethnicity & Naxi & Jingpo & $\begin{array}{c}\text { Bulan } \\
\text { g }\end{array}$ & Pumi & $\begin{array}{c}\text { Achan } \\
\text { g }\end{array}$ & Nu & $\begin{array}{c}\text { Jinu } \\
\text { o }\end{array}$ & Deang & Dulong \\
\hline $\begin{array}{l}\text { Illiteracy/ } \\
\text { Semi-illiteracy }\end{array}$ & 7.20 & 9.62 & 14.62 & 14.77 & 8.28 & 16.13 & 9.20 & 19.63 & 16.92 \\
\hline $\begin{array}{l}\text { Higher } \\
\text { education }\end{array}$ & 11.46 & 3.70 & 3.42 & 7.77 & 4.67 & 5.68 & 6.21 & 2.06 & 5.98 \\
\hline
\end{tabular}

The data showed that a considerable gap still existed between the Han majority and the EEMs at both a low and high level of education. The EEMs' illiterate/semi-illiterate people (11.96\%) were almost double that of the Han $(6.86 \%)$, while Han's higher education students were $2.41 \%$ higher than those of the EEMs. Among the 15 EEMs, Naxi, Bai, and Pumi's proportions of higher education were a little higher than the Han, and Naxi had the highest ratio of students who accessed college or university. However, some EEMs such as Lisu $(2.60 \%)$ and Deang $(2.06 \%)$ had a deficient proportion in higher education, whereas the illiterate/semi-illiterate ratios were very high. It showed that "poverty and illiteracy always come together and feed each other, and this circle needs to be broken" (Wan \& Jun, 2008, p.148).

The 15 EEM groups were chosen on purpose as samples to represent ethnic minority groups in Yunnan which were rationalized before. The low education level inevitably hinders the local socioeconomic development. Through later interviewing, it was found that some other factors were determining the necessity of implementing PAPs for ethnic minorities in the NCEE. In the following data, geographical remoteness and regional gaps, socioeconomic determinants, linguistic barriers, etc. are prominent. Within these factors usually brings forth the fundamental problems causing the academic differences among different ethnic minority groups.

\subsection{Three determinants of PAPs in Yunnan}

\section{Geographical Remoteness and Regional Gaps}

For historical reasons, most ethnic minorities live in nomadic pastoral localities, mountainous highlands, and border areas, where geographical conditions severely restricted economic development. Although there are many supportive policies to enhance Yunnan's socioeconomic reforms, uneasy living and educational conditions still largely exist, and geographical remoteness often 
results in educational disparities for minority students. From a geographic perspective, poor transportation in mountainous areas increases the difficulties for minority students' schooling. The data show that EEM students' locations or origins have gradually become a key element in the implementation of PAPs. Those minority students need bonus points in their NCEE, which allows them priority in university admissions over most Han students even when all the other criteria are the same. A Lisu student from the Nujiang ethnic community revealed that in his childhood, he and his fellow students often walked a long distance to school and the conditions in his primary school were poor:

I still remember when I was at primary school, there was only one classroom for two classes, and only three teachers. One was female, the others were male. (Lisu S-2, KUST-Y2)

Nujiang's poverty ratio was $38.4 \%$, almost ten times that of the average for China, and that leads to a high dropout rate as well. (Han Offical-2, $K E B)$

In the interview, $\mathrm{Mr} \mathrm{He}$, who had abundant working experience for ethnic minorities, said:

Nevertheless, how to work well with the introduction of good school teachers is a hard task since difficult mountainous conditions usually hinder teachers' personal development. (Naxi Official-1, YPDE)

This finding agreed with Gil and Adamson (2011) who emphasized that a lack of access to good facilities and qualified teachers usually resulted in minority students becoming poorer performers than most of their Han counterparts (Gil \& Adamson, 2011). In Yunnan, minority education development varies from one autonomous ethnic area to another. A Hani student mentioned that different education conditions of ethnic areas to a large extent resulted in the differences in the implementation of PAPs:

We have different education platforms. Surely PAPs are in need. (Hani S-6, KUST-Y3)

Besides, the regional disparity between the rural and urban areas in autonomous ethnic areas is also increasing. Compared with urban regions, many rural areas have fallen behind in economic, educational, and medical services and developments, and a large proportion of rural areas remained in poverty. Most interviewees confirm that the educational gap is mainly derived from regional disparities. Conversely, regional education disparities are inclined to be enlarged with the fast-economic growth.

I think the imbalance of high-quality education resources that are allocated between the city and rural areas also enlarges the gap between the Han and the ethnic minorities. (Zhuang Adm-1, YMU)

In such a highly competitive country like China, educational development is greatly influenced by some social determinants, particularly economic development. Cultural differences among different areas and various ethnic groups also play a critical role in education. It is consistent with what $\mathrm{Li}$ et al. (2015) pointed out. He stated that after mass college expansion to higher education in 1998 in China, rural youth from remote counties had less 
opportunities to go to college or the elite Project 985 and 211 universities $^{4}$ than urban youth. There were even more significant gaps existing for disadvantaged subgroups of rural youth from poor counties, such as female or ethnic minority children (Li, et al., 2015).

The necessity of PAPs in the NCEE for higher education should be traced back to primary education. In recent years, competition in examinations in China has shifted from university entrance down to junior/senior high schools, and even to primary schools. Enrolment in a key high school is now construed almost as a dependable guarantee to enter college or university. It demonstrates the importance of school conditions in children's education. However, most minority students typically have no access to key schools unless they happen to live in those urban areas.

The farther away from cities, the fewer resources a school has. The fewer resources a school has, the less it prepares its students academically for Gaokao (NCEE). (Bai Adm-2, DU)

In Yunnan, one of the problems is severe poverty in some areas which manifests itself in a small number of economic development opportunities and limited educational resources due to ethnic and regional disparities and low quality of local education systems. In China, the NCEE plays an important role in not only reallocating educational resources but selecting talent for higher education. Under the present circumstances, PAPs fill the regional gaps and increase the proportion of higher education for more ethnic minorities which, in no small degree, will determine their future academic and professional development.

\section{Socioeconomic Determinants}

The rapid socioeconomic development of China in the past decades has provided ethnic minorities with both chances and challenges in overall development. All the preferential policies have strongly promoted the improvement in the livelihood of people in ethnic minority regions. But comparatively slower economic growth in Yunnan still results in a lower educational investment in minority areas. Reversely, lower level of education hinders Yunnan local socioeconomic development. And it also causes poverty and lower literacy conditions in some ethnic groups. Even as the overall level of poverty has dropped, new inequality has increased. Practically, social determinants play a critical role in the educational development of ethnic minorities, particularly, economic development and cultural differences among different regions and various ethnicities.

Economically speaking, educational quality is inseparable from economic growth because education requires a good deal of financial input to provide sufficient resource including qualified teachers and teaching facilities, etc. (Han Official-2, KEB)

4Project 211 and 985 are projects of key national universities initiated in 1995 and 1998, respectively, by the Ministry of Education (MOU) of the PRC in an endeavour to found world-class universities in the $21^{\text {st }}$ century. 
As Verhoeven and Zhang (2016) state that, the economic development of territories in the remote mountainous areas, border areas, and pasturing areas in the western parts of China lags far behind the national average level (Verhoeven \& Zhang, 2016). Yunnan's situation exemplifies this. The relative lagging of economic development of Yunnan mainly lies in its weak foundation in talent resources. Inadequate educational investment is destined to affect school conditions and therefore, the general quality of education. Under such circumstances, both the central government of China and some local, provincial governments like Yunnan have started to pay more attention to ethnic affairs than previously.

Besides, agriculture and livestock are the primary sources of economic development in minority areas in Yunnan. Concentrated areas of ethnic minorities, in particular, depend on agriculture. As described by some interviewees, most ethnic villages in the rural areas of Yunnan continue to use very traditional farming methods with cattle and horses. Consequently, a small employment market and some underdeveloped industries impose a relatively low demand for high-quality labour and technology.

Some of us [EEM students] cannot concentrate on our study because we have to labour in the fields for our parents. (Dai S-6, DU-Y1)

On the one hand, most rural ethnic minority families depend on farming and labour for herding or subsistence agriculture. Parents often have to make a living by farming, and thus the labour of all family members is critical to their survival. On the other hand, the illiterate rural parents can at most support their children to go to school but not help with the children's studies even if they want to. Lacking guidance of family education and parents-cultivated cognitive strategies to manage schoolwork often degrades the ethnic minority students' school records and increases their difficulties to be academically successful. To some degree, this lack of development limits local people's views of education, which in turn impedes a positive motivation on minority students' learning during school days. Two teachers from YMU and KUST commented that:

Families cognitively/ culturally influence their children's education. Also, poor minority families cannot financially support their children's education. (Zhuang T-1, YMU)

I believe PAPs just attempt to put students from different socioeconomic and educational backgrounds on an equal footing in the competition for higher education. (Han T-2, KUST)

The three administrators from YMU, DU and CNU stressed that the purpose of higher education for ethnic minorities was to cultivate more professional talents to serve sustainable cultural and socioeconomic development in the concentrated areas of ethnic minorities. It was vital to maintain the stability of China, a state with multiethnicity, achieve equality and mutual respect among different ethnic minorities, and ultimately promote cultural retention and adaptation. Those minorities with a higher proportion of higher education usually have more advanced social cultural and economic development in their regional construction. Through the focus group interview, it was confirmed that Bai and Naxi people have a comparatively higher level of education than most of 
the other minorities in Yunnan. With a long history and their scripts, i.e. Baiwen and Dongba, Bai and Naxi ethnic groups are culturally advanced. While Deang students like to discuss their cooking traditions as well as board and lodging etiquette rather than science or technology. Their language belongs to the South Asia family but lacks any script. The Yunnan government encourages minority university graduates to return to their hometowns by offering special provision programs to "targeted-area students". It means PAPs mandate lowered cutoff score for college applicants from specially targeted concentrated areas of ethnic minorities on the premise that these students commit to returning to work in the targeted areas upon graduation.

PAPs state that college applicants who commit to working in 25 counties along Yunnan's borders and three counties in Diqing prefecture after their graduation will receive an additional five bonus points on the NCEE. And for members of any ethnic group with a population smaller than one hundred thousand, an additional ten bonus points will be rewarded. (Naxi Official-1, YPDE)

However, despite PAPs having been implemented for decades, gaps that result in ethnic minority students lagging behind in primary education later hinder the general level of minority education. The effect of the considerable difference in socioeconomic development has led to low investment at all levels of educational sectors. Yunnan is a typical province in this case. Some ethnic minority parents hold the view that it is too costly to send their children to college and then remove them from schooling at an early age. Unfortunately, many youths from the remote and poor mountainous rural areas drop out of junior high school. Furthermore, the number of female teachers in the ethnic regions is relatively small, which has greatly affected the education for both girls and women, and hindered the development of female teachers.

\section{Linguistic Barriers}

Yunnan encompasses the minority groups' native languages (L1), Mandarin Chinese (L2), and a foreign language, typically English (L3). The multilingual environment creates a triangular complex that increases possible policy configurations nowadays. But the implementation of bilingual and trilingual education still needs to be improved.

Concentrating on the ethnic assimilation and ethnic pluralism, bilingual or trilingual education is essential to cultural integration and cultural pluralism. Although progress has been made, shortage of qualified bilingual teachers and, at a later stage, trilingual teaching resources, add to the difficulties that ethnic minority students have to confront with at school. For example, a Bulang student recalled his bilingual learning as follows:

We (Bulang children) had to read Chinese textbooks and immerse them in Mandarin instruction as soon as we started primary school. We could do as well as our Han classmates at the very beginning, but gradually fell behind because language became an increasingly formidable barrier. (Bulang S-4, YMU-Y3) 
Standard Chinese (Mandarin) is a compulsory course for all Chinese students from primary education. School curricula now require all pupils, including ethnic minorities, to study Chinese. Mandarin Chinese is not only the national language, but also a prerequisite for school education. Strenuous efforts have been made to promote national cohesion and unity through popularizing Putonghua as a lingua franca in China. With the emphasis on teaching and using Mandarin in minority primary schools, the pressure on minority students to learn L2 is unavoidable. A Jingpo MA student who majored in Humanities specified the situation as follows:

Mandarin Chinese is difficult for me... [em] My [L2] writing proficiency is weak, and I often find my writing is without originality and creativity. In senior high school, my maths and physics were poor too. Our teacher always criticized me for not reading and analyzing questions clearly. (Jingpo S-3, YMU-MA1)

Some participants stated that L2 deficiency in practice affected minority students' regular school performance, but more importantly, influenced their academic score in the NCEE. For some minority students who especially grew up in concentrated ethnic communities where Chinese was hardly spoken, they were less competent and competitive than their Han counterparts. It is an essential factor that puts minority students at a disadvantage both in local school education and in national examinations.

In our village, people all talk to each other in Dai or some in the Lincang dialect. Those teachers of the village primary school didn't speak Mandarin as well. My Chinese scores in the NCEE were only 82 points [out of the total 150 scores], so I nearly failed to enter university. (Dai S-2, KUST-Y1)

Although under high pressure to learn L2, ethnic minority students are obliged to study Mandarin Chinese on all accounts. The government's policy is to promote bilingual education in concentrated areas of ethnic minorities. However, Mandarin Chinese must be given priority.

Bilingual education is necessary at the starting point of education. But after middle school, it is formulated by the Ministry of Education (MOE) that Mandarin Chinese is the only language of instruction [except for English class]. [Mandarin] Not only helps them get more chances of higher education, but have better job opportunities after graduation. (Naxi Official-1, YPDE)

Also, Yunnan is one of the provinces in the west with the most limited English teaching resources in China. In many primary or secondary schools that ethnic pupils attend, mostly due to a severe shortage of qualified English teachers, opportunities for ethnic minority students to learn English (L3) are scarce.

When I was at primary school, there was no English class offered. In secondary school, we had a substitute English teacher. He was not an English graduate, but a graduate in maths...I was hopeless in English grammar, always feeling confused... Now at university, I can't follow. The English teachers all speak English in class. 
The teaching of L2 and L3 was introduced in a top-down manner through the medium of China's national language policies into the curricula and practices of local schools and universities. Especially at a basic level of education, the experience of ethnic minority students in developing their language proficiency often lacks symmetry. Furthermore, what the data from EEMs reveal is that the students' language deficiencies later even create difficulties in comprehending those increasingly complicated school textbook materials when they study other subjects like physics, mathematics etc. Unfortunately, it undermines minority educational performance overall. Yunnan ethnic minority learners encounter the dilemma that bilingual education is mainly implemented only in primary schools. When students enter in secondary schools and universities, all school formal education in L1 stops. The discontinuity results deficiency in both languages for ethnic minority students. Moreover, it was found that L3 often started from junior secondary school in most places in Yunnan. Trilingual education at the higher education levels in China, not only in Yunnan, is conspicuously absent. The sense of being on an unequal footing with majority Han students and thus of being disadvantaged seemed to prevail among the EEM interviewees. It has to be noted that concerning the minority groups in Yunnan, these students have to take the NCEE in their L2, and L3 is also another compulsory exam- course in the NCEE.

\section{Implications of the Study}

This study highlights the necessity for the implementation of PAPs in the circumstances of Yunnan's multi-ethnic but low-level minority education. To redress these unfavourable constraints requires multi-dimensional interventions by the government, schools, and ethnic minorities themselves, including their communities and families in the context of Yunnan. Based on this study, three types of implications are proposed.

\subsection{Pedagogical Implications}

Since schooling at a primary education level is one of the most influential factors fundamentally contributing to ethnic minority students' unsatisfactory academic achievements and eventually in their NCEE performance (Wang, 2009), some problems are emphatical to be addressed.

First, priority should be given to solving the problem of teacher shortages in ethnic rural areas and strengthening professional teacher training programs with special compensation packages provided for teachers' personal development, including substitute teachers who work in compact ethnic minority areas. Besides, as is revealed by the study, regional disparity between the rural and the urban frequently enlarges the educational gap. Thus, it is highly suggested that the Yunnan local government consider providing more substantial financial support by explicitly targeting ethnic minority regions, especially in the mountainous, border, and rural areas, to strengthen the equipment of teaching facilities and reduce the gap. For some poverty regions such as Nujiang etc., more boarding schools can be set up for students who are from border areas starting from primary school due to the geographical remoteness $(\mathrm{Li}, 2014)$. It 
may help consolidate schooling and provide a practical option for nomadic students in sparsely populated and remote areas.

Second, although the research was carried on the node of the NCEE, it also uncovered that similar educational opportunities for ethnic minorities should not be confined to a fair admission to higher education after the NCEE. Instead, equal education platforms should be reflected at starting points, processes, and achievements from primary school. The actual difficulties in minority education, especially in providing educational resources, require that a more systematical minority education be tackled with an ultimate purpose of bridging the educational gaps between different ethnicities where regional disparities still exist. Moreover, at a higher education level, universities should consider offering various elective courses to help minority students make a smooth transition from primary education to higher education, and adapt to a uniform academic assessment system at the tertiary level. Universities with ethnic culture programs, like YMU, DU, and CNU, etc., should be aware of the significant disadvantages of minority students caused by external factors and make more considerable efforts to promote equal educational opportunities for them.

\subsection{Socioeconomic Implications}

Economic support for education is necessary to mobilize a series of improvements with well-qualified teachers, excellent teaching facilities, and even the enhancement of relevant research on minority education, which the academic success of minority students is dependent on.

First, all higher education institutes in China started to charge fees since 1996, and tuition fees have continued to rise. Rising college tuition fees have become too high for some ethnic minority families to afford (Hayhoe, 2011), and this prevents many poor rural minority students from continuing their higher education (Li, et al., 2015). PAPs should not only focus on college admission, but also help minority university students complete their academic attainments with various stipends or scholarships after they enter universities. In particular, effective measures should be taken to encourage more ethnic graduates to help develop local social economies and to bridge the gap between rural and urban areas in education.

Second, as China's education system is extremely competitive, it has to be noted that with the expansion of higher education, Yunnan ethnic minority students are also facing unprecedented competition from Han majority and even other ethnic minority groups with better social and economic backgrounds and educational conditions. College graduates face a tough job market in recent year, and those with better education background will have more opportunities for career development. Differences in access to college will continue to be a significant obstacle in achieving social equality and intergenerational mobility. Higher education institutions can play a much more active role in promoting multilingual and multicultural education by giving more emphasis to both social integration and individual ethnic differences. 


\subsection{Language Ecological Implications}

Linguistically, in Yunnan, except for the Hui, Man, and Shui minorities who use Mandarin Chinese, other minorities speak 25 languages, have 22 written scripts, and almost 6 million ethnic minority people are not able to speak Mandarin Chinese (Dao \& Hu, 2005). Language, as an essential instruction medium at school, is the most prominent determinant influencing the level of minority education in a cultural perspective (Wang, 2015).

First, Yunnan's multi-ethnic social context is well-suited to bilingual, trilingual, and even multilingual education, which is underpinned by the characteristics of minority students' different ethnic language backgrounds. Trilingual education can play a decisive role in both social and economic development, and it can provide a boost to cultural tourism in Yunnan as well, in which the links between L1 and L2 can be effectively connected. Briefly, for a minority group, L1 is crucial for maintaining their linguistic and cultural heritage, ethnic identity, and the cognitive development of their children (Gynan \& Baker, 2011). L2 is equally vital for social and economic integration, and L3 helps engage with internationalization. However, some factors in bilingual or trilingual education need to be emphasized. On the one side, the constant spread of the high status accorded to L2 and L3 imposed an external pressure on the minority languages (L1), which have the low social status due to the lack of associated economic and political capital. L1 is becoming endangered while L2 and L3 are still reinforced by systemic education mechanisms, such as the NCEE. On the other side, the realistic situations should be considered, such as a lack of comparatively useful resources, including qualified bilingual or trilingual teachers, teaching resources, and trilingual learners' difficulties in L3 acquisition in an EFL (English as a foreign language) environment especially when ethnic minority students' L1 and L2 have not been fully developed.

Second, China's "The Belt and Road" (B\&R) policy has shifted Yunnan from a border province to the forefront of reform and is opening it up to Southeast Asia. The coexistence of the three languages that ethnic minority people face in Yunnan pushes them to take on the acquisition of L2 and L3. Moreover, L3 has become an interlanguage between the local and global perspectives. The local economies are woven into a global economy, including the flow of labour, goods, tourism, and capital. When L2 and L3 become increasingly more dominant than before, minority languages are endangered because promoting these two languages can lead to cultural and linguistic imperialism (Ludwig, Pagel \& Mühlhäusler, 2018). Accordingly, it is suggested that the government add some specific and supplementary regulations into preferential policies to protect minority languages, especially those of small ethnic groups, to boost the language vitality of their L1. At the same time, in minority education practice, bilingual or trilingual education is a necessary procedure to improve the ecological balance of multi-languages in Yunnan. 


\section{Conclusion}

For decades, Yunnan's education level has been comparatively lower than that of many other provinces in China. PAPs intend to put minority students from different socioeconomic backgrounds on an equal footing in higher education at the critical moment of the NCEE. PAPs have helped a significant number of ethnic minority students to become beneficiaries with better education opportunities at university. Meanwhile, PAPs contribute to restore education equality, compensate for the cultural tilt of the test toward fairness. This research project is in agreement with the necessity of PAPs due to the geographical remoteness, regional gaps, socioeconomic determinants, and linguistic barriers of Yunnan ethnic minorities. Based on the data analysis, PAPs are currently justified in Yunnan's multi-ethnic social context and are indeed a significant step towards ethnic equality in education. These policies provide considerable help to ethnic minorities, especially to those whose academic attainment is not sufficient for the NCEE owing to the external constraints of society, school, and family, which are concurrently intertwined, to achieve equality in higher education. However, PAPs are not a fundamental solution to the ethnic education problem. Gaps still exist between the implementation of PAPs and expectations. Even though the local government is supportive of minority students and willing to accommodate their needs, especially at higher education level by PAPs, limited education investment often paralyzes students' academic careers. This study calls for a more comprehensive set of policies for PAPs, including issues of pedagogy, social economy, and even cultural and linguistic diversity itself. Both the government and educators should be increasingly aware of the great importance of bridging the relevant gaps in the education of ethnic minorities in a modernized and multi-ethnic Yunnan, China.

\section{Acknowledgement}

The researchers would particularly extend thanks to Suranaree University of Technology, Thailand; Also, Dongyuan Deng would like to express her gratitude to the support of the National Social Science Fund of China (Grant No. 19XYY003), and the sponsor from research projects (Grant No. SKPJ201813; skpyzd201704).

\section{References}

Adamson, B., \& Feng, A. (2009). A comparison of trilingual education policies for ethnic minorities in China. Compare, 39(3), 321-333.

Adamson, B., \& Feng, A. (2014). Models for trilingual education in the People's Republic of China. In D. Gorter et al. (Eds.), Minority languages and multilingual education (pp. 29-44). Dordrecht: Springer.

Adamson, B., \& Xia, B. (2011). A case study of the college English test and ethnicminority university students in China: negotiating the final hurdle. Multilingual Education, 1(1), 1-11.

Ba, Z. (2009). Using Yugur in local schools: reflections on China's policies for minority language and education. In Zhou M. \& A. M. Hill (Eds.), Affirmative Action in China and the US (pp. 199-209). New York: Palgrave Macmillan.

Bao, R., \& Liu, N. (2015). Content analysis of the national college entrance examination 
bonus point policy since the reform and opening up. Journal of Higher Education Management, 9(5), 30-35.

Cai, Y. (2014). Looking at the future of China's population from the sixth national population census and United Nations population projections. Chinese Research Perspectives on Population and labour, 1. Boston: Brill Academic Publishers.

Campos, B. C., Ren, Y., \& Petrick, M. (2016). The impact of education on income inequality between ethnic minorities and Han in China. China Economic Review, 41, 253-267.

Chen, L. (2019). The retrospect and prospect of the research on the policy of awarded marks for minority examinees in the college entrance examination. Education and Examinations, 3, 10-15.

Dao, F., \& Hu, F. (2005). An analysis of the 25 ethnic minorities education situation in Yunnan. Journal of Honghe College, 2(1), 84-88.

Dong, F., Gou, Y., Wang, X., \& Qiu, J. (2015). Four models of Mongolian nationality schools in the Inner Mongolian Autonomous Region. In Feng A. \& B. Adamson (Eds.), Trilingualism in Education in China: Models and Challenges (pp. 25-45). Dordrecht: Springer, Netherlands.

Feng, Y., \& Cheung, M. (2010). Public policies affecting ethnic minorities in China. China Journal of Social Work, 1(3), 248-265.

Finifrock, J. E., \& Schilken, D. (2015). Emerging trilingualism among the Dong minority in Guizhou Province. In Feng A. \& B. Adamson (Eds.), Trilingualism in education in China: Models and challenges (pp. 199-221). Dordrecht: Springer, Netherlands.

Gil, J., \& Adamson, B. (2011). The English language in mainland China: A sociolinguistic profile. In A. Feng (Eds.), English Language Education Across Greater China (pp. 2345). New York: Multilingual Matters.

Gladney, D. C. (1994). Representing nationality in China: refiguring majority/minority identities. Journal of Asian Studies, 53(1), 92-123.

Gorter, \& Durk. (2015). Multilingual interaction and minority languages: proficiency and language practices in education and society. Language Teaching, 48(01), 82-98.

Guan, H. (2019). The constitutional regulation over the policy of awarded points in China's college admission system. Journal of Nanjing Normal University (Social Science Edition), 3, 106-115.

Guo, A., Ding, X., Zhong, F., Cheng, Q., \& Huang, C. (2019). Predicting the future Chinese population using shared socioeconomic pathways, the sixth national population census, and a PDE model. Sustainability, 11(13), 3686. https://doi.org/10.3390/su11133686.

Gynan, S. N., \& Baker, C. (2011). Foundations of bilingual education and bilingualism. Modern Language Journal, 78(3), 390.

Hayhoe, R. (2011). Higher education reform in China: beyond the expansion (review). China Review International, 18(2), 220-224.

Hill, C. E., Knox, S., Thompson, B. J., Williams, E. N., Hess, S. A., \& Ladany, N. (2005). Consensual qualitative research: An update. Journal of Counseling Psychology, 52(2), 196.

Hu, Y., \& Ga, Y. (2016). Correct understanding of bonus points for ethnic minorities in the college entrance examination. Journal of South-Central University for Nationalities (Humanities and Social Sciences), 36(5), 18-22.

Li, H., Loyalka, P., Rozelle, S., Wu, B., \& Xie, J. (2015). Unequal access to college in China: How far have poor, rural students been left behind? The China Quarterly, 221, 185-207.

Li, X. (2014). Questioning China's preferential college admission policies. Widening 
Participation and Lifelong Learning, 16(1), 70-90.

Ludwig, R., Pagel, S., \& Mühlhäusler, P. (Eds.). (2018). Linguistic ecology and language contact. Cambridge: Cambridge University Press.

Mackerras, C. P. (2003). China's Ethnic Minorities and Globalization. London: Routledge.

National People's Congress. (2018). Higher education law of the PRC (Revised). Higher Education in China, 10, 2-5.

Nunkoosing, K. (2005). The problems with interviews. Qualitative Health Research, 15(5), 698-706

Postiglione, G. A., Jiao, B., \& Tsering, N. (2009). Tibetan student perspectives on Neidi schools. In Zhou M. \& A. M. Hill (Eds.), Affirmative Action in China and the US (pp. 127-142). New York: Palgrave Macmillan.

Sautman, B. (2010). Ethnic law and minority rights in China: progress and constraints. Law \& Policy, 21(3), 283-314.

Sun, Y., Ren, Z., He, Y., \& Zhu, H. (2013). Factors influencing rural teacher flow in Yunnan ethnic minority areas. Asian Agricultural Research, 5(8), 93-97.

Sunuodula, M., \& Cao, Y. (2015). Language learning and empowerment: Languages in education for Uyghurs in Xinjiang. In Feng A. \& B. Adamson (Eds.), Trilingualism in Education in China: Models and Challenges (pp. 65-99). Dordrecht: Springer, Netherlands.

Sunuodula, M., \& Feng, A. (2011). Learning English as a third language by Uyghur students in Xinjiang: A blessing in disguise. In Feng A. (Eds.), English Language Education Across Greater China (pp. 260-283). New York: Multilingual Matters.

Teng, X., \& Ma, X. (2009). Preferential policies for ethnic minorities and educational equality in higher education in China. In Zhou M. \& A. M. Hill (Eds.), Affirmative action in China and the US (pp. 83-98). New York: Palgrave Macmillan.

Verhoeven, J. C., \& Zhang, J. (2016). The pathways to higher education for ethnic minorities in China are not easy. In Lee, J., Yu. Z., Huang, X., \& Law E. H. (Eds.), Educational Development in Western China: Towards Quality and Equity (pp. 121135). Rotterdam: Sense Publisher.

Wan, G., \& Jun, Y. (2008). How China best educates its ethnic minority children: strategies, experience and challenges. In Wan G. (Eds.), The Education of Diverse Student Populations (pp. 139-157). Dordrecht: Springer.

Wang, G. (2015). Ethnic multilingual education in China: A critical observation. Working Papers in Educational Linguistics (WPEL), 30(2), 3-15.

Wang, T. (2009). Preferential policies for minority college admission in China: Recent developments, necessity, and impact. In Zhou M. \& A. M. Hill (Eds.), Affirmative action in China and the US (pp. 71-82). New York: Palgrave Macmillan.

Yang, J. (2005). English as a third language among China's ethnic minorities. International Journal of Bilingual Education and Bilingualism, 8(6), 552-567.

Yuan, Y., Hu, D., Li, P., Zhu, H., Wang, J., Shang, Y., \& Ba, H. (2015). A survey report on trilingualism and trilingual education in Yunnan. In Feng A. \& B. Adamson (Eds.), Trilingualism in education in China: models and challenges (pp. 175-198). Dordrecht: Springer, Netherlands.

Zhou, M. (2009). Tracking the Historical Development of China's Positive and Preferential Policies for Minority Education: Continuities and Discontinuities. In

Zhou, M., \& Hill, A. M. (Eds.). Affirmative Action in China and the US (pp. 47-70). New York: Palgrave Macmillan. https://doi.org/10.1057/9780230100 


\begin{abstract}
About the Authors
Dongyuan Deng is an associate professor at Kunming University of Science and Technology, China. She was a visiting scholar at the University of Alberta, Canada, and now is a PhD at the School of Foreign Languages, Suranaree University of Technology, Thailand. Her academic interests include language planning and policy, ethnic minority multilingual education, EFL teaching and learning. Presently she is hosting the National Social Science Fund of China (Grant No. 19XYY003).
\end{abstract}

\title{
Corresponding Authors:
}

Sirinthorn Seepho was awarded her Doctor of Philosophy (Foreign Language Education) from the University of Pittsburgh, USA. Her academic specialties include English Language Teaching, Teacher Training, Content-based Instruction, English as a Medium of Instruction, and Qualitative Research.

Andrew Lian is the President of AsiaCALL (Asia Association of ComputerAssisted Language Learning) and currently Professor of Foreign Language Studies in the School of Foreign Languages, Suranaree University of Technology, Thailand. He was awarded his doctorate (French Language and Literature) by the University of Paris IV-Sorbonne, France. His research interests are computerassisted language learning (CALL), neurolinguistics, and language learning theories. 